\title{
Tooling Design of Milling Compounding Machine
}

\author{
Wen Ju SHAN ${ }^{1, a}$, Li Yu GUO ${ }^{1}$ \\ ${ }^{1}$ Zhuhai College of Jilin University, 519041Zhuhai, China
}

\begin{abstract}
Professional tooling design is one of the most important part of the Milling Compounding Machine design. This paper mainly introduces the fundamental process of the tooling Design of Milling Compounding Machine, which includes the choosing of tooling material, the development and the chosen principle of tooling structure, the chosen principle of the milling cutters, and the geometry design of the cutters etc. it has certain significance for the practice production discussed.
\end{abstract}

\section{Introduction}

Machining and tooling technology is the key element of advanced equipment manufacturing industry, which plays an important role in the revitalization of China's equipment manufacturing industry. We must make full use of the machining and tooling technology. Tooling Design is an important part of the design of modular machine tool. The tool design includes the chosen of tool material, the chosen of tool structure and the design of the whole tooling system.

Compared with general machine, the combination machine has certain limited using conditions for the tools, which makes the combination machine tool to adapt a variety of specific conditions, besides the general characteristics of ordinary machine tool. [1] The general machine tool requires a full use range, while the combination machine tool requires higher reliability, longer life time and convenience in adjustment and disassembly due to producing specific parts. The compounding machine has high production efficiency, the tools' running time for single workpiece is shorter, and supposing that the tooling changing and adjusting takes a long time, the whole machines' efficiency will be reduced. So in the process of machining, the requirements of compounding machine tool are as following:

1) The reasonable structure of the tooling to ensure the produce quality of workpiece

2) According to the characteristics of the workpiece, select proper material and suitable parameters of the cutting tool to ensure the durability of the tool

3) Convenient in disassembly and adjustment. The tool can be adjusted and changed in a relatively short time for the higher production efficiency.

\section{Selection of milling cutters materials}

The cutting performance of the tool is first determined by its material. The first in the design of the tool is to select the tool material. The tool material determines the performance of the tool. According to the specific type of tool, combined with the specific processing parts to select the appropriate tool material, and then according to the performance of the tool to determine the reasonable cutting parameters, so as to achieve the best cutting effect.

The material of the cutting tool plays a key role in the cutting performance. Modern cutting tool materials has a constant development, from tool steel, high speed steel, development to hard alloy, high performance ceramics, super hard materials etc. Heat resistant temperature has a higher improvement, from 600 degrees to more than 1200 degrees. The allowing cutting speed has more than $1000 \mathrm{~m} / \mathrm{min}$, The cutting efficiency is improved by more than 100 times in the past less than 100 years.

In the metal cutting process, the cutting part of the tooling is in the condition of high temperature, high pressure, friction, shock and vibration and other harsh occasions. From the service life of the tool, the performance requirements of the tool material are mainly the wear resistance, strong toughness, and high temperature red - hardness and so on. Different types of tools and processing conditions requires different tool. Generally speaking, cutting tool material should have the following properties: enough hardness, enough strength and toughness, enough wear resistance and heat resistance, manufacturability and economy, etc...

With the development of materials science and engineering, to meet the needs of a variety of functions, advanced metal or non-metallic materials emerge in an endless stream, such as model materials in aerospace, nuclear materials, biological materials, nanometer materials, rare earth materials. [2] Facing a wide variety of engineering materials, to improve the productivity, reduce processing costs and reduce the consumption of

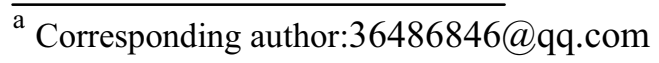


resources, need to choose the right tool material for cutting.

Different tool materials or the same kind of tool processing different workpiece materials, cutting effect will often differs. Each tool material has its specific processing range, which can only adapt to a certain part of the workpiece material and a certain range of cutting parameters, in the other word, cutting tool material and workpiece material has the problem of reasonable match. The matching of cutting tool material and workpiece material mainly refers to the physical properties, mechanical properties and chemical properties of the two parts. According to the reasonable selection of cutting tool material, the ideal machining efficiency and low production cost can be obtained.

1) Match the physical properties of tool material and workpiece material. The physical characteristics of the cutting tool determine the workpiece material which is suitable for processing. For example, a poor thermal conductivity of workpiece needs a tool material of good thermal conductivity in order to facilitate the cutting heat spread quickly and reduce the temperature of the cutting area.

2) The mechanical properties of tool material and workpiece material are matched, mainly refers to the strength, toughness and hardness and other mechanical properties parameters.

3) The chemical properties of tool material and workpiece material are matched, mainly refers to the tool material and workpiece material chemical affinity, chemical reaction, diffusion and dissolution of chemical performance parameters. When tool material and workpiece material works in high temperature, chemical reaction occurs, chemical dissolution and diffusion elements between the tool and the workpiece. The tool occurs the oxidation wear and diffusion wear and chemical wear, especially in high speed cutting and the high temperature, the chemical wear is far more serious than the abrasive wear caused by mechanical wear.

At present, high speed steel, hard alloy, metal ceramics, ceramics, diamond and cubic boron nitride are widely used in cutting tool materials. With the development of metal cutting tool surface modification technology, coating tools used more and more widely used.

Tool surface coating technology is mainly through chemical or physical vapor deposition method, the tool surface to obtain a few microns to ten microns thick hard film. Hard coating has high hardness, good lubrication, excellent high temperature performance characteristics, so that cutting tool can achieve excellent comprehensive mechanical properties, a substantial increase in the cutting speed and the cutting dosage, high quality for the machined surface.

\section{Selection of special milling cutter structure}

Milling is a very common way of processing. Through the rotation of the Multiple cutting edge tool (cutting edge around its own axis of rotation of the main cutting edge movement), feed motion along the direction of the workpiece, thereby completing the metal cutting, forming the machined surface. Milling has the following characteristics: milling is a continuous cutting, the impact load is large, easy to produce vibration, the cutting thickness and cutting area in the cutting process is changing, and the cutting force is changed greatly. In milling, the total length of the cutting edge is longer, the milling area is relatively wide, the metal removal rate is high, and so the productivity is high. [3]

According to the whole structure, milling cutter can be divided into integral milling cutter, welding carbide milling cutter and Mechanical clamping indexable milling cutter.

1) The integral-type milling is the cutter tooth and cutterhead using the same material as a whole made of milling cutter.

The whole cylindrical cutter has spiral teeth on the surface and a cutter tooth on the end, while milling, mainly use spiral teeth on the surface for cutting. In the rough machining and other large margin occasions, the chip can be worn out of the main cutting edge to smooth chip removal. In machining process, if the blade wear or damage, integral type milling cutter need to replace the entire milling cutter, after installing the new cutter need to reset the tool. Replacing the tool takes a long time, which will affect the overall processing efficiency of the combined machine tool.

2) Welding hard alloy milling cutter generally refers to the cutter tooth welding on the cutter body.

The material of the cutter tooth is generally used for hard alloy or other good performance tool material, including welding carbide helical tooth end milling cutter, welding carbide helical tooth milling cutter, welding carbide helical corn milling cutter, etc. The advantage of welding carbide milling cutter is the simple structure, easy manufacture, low cost of the material. However, the precision of the milling cutter is affected by the welding technology, and after the tool wear, Need to replace the whole tool, Tool change time is long, the processing efficiency is low.

2) The machine clip indexable blade is fixed on the cutter body by a mechanical fixing method. General use perforated blade with clamp screw, Simple structure, large chip space.

The machine clip blade has good impact resistance, which is suitable for large cutting depth and fast feed, high production efficiency. The blade can be replaced, no need to regrinding and recoating, and the economic performance is better. In the cutting process, when a certain blade wears, the corresponding blade can be adjusted to continue processing, which greatly improves the use rate of the blade, reduces the time and the number of re adjustment. Also due to the blade is standardized in large quantities and centralized production and the size of each blade are the same, the tool is changed without resetting and can improve the productivity of machine tools.

\section{Type of machine clip indexable blade}


The machine clamp indexable blade mainly includes end mill, Face milling cutter and three face milling cutter.

The main cutting edge of the end milling cutter is in a cylindrical surface, and the cutting edge of the end face is auxiliary blade.

End mill is shown in Figure1

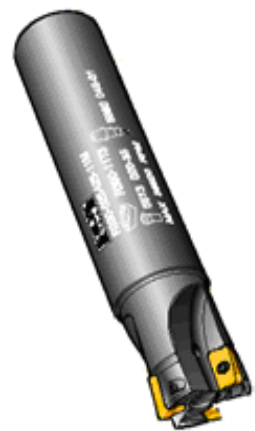

Figure 1. End mill

The difference between a face milling cutter and an end mill cutter is the diameter, an end mill with a diameter greater than $40 \mathrm{~mm}$ is called a face milling cutter.

Face milling cutter is shown in Figure2

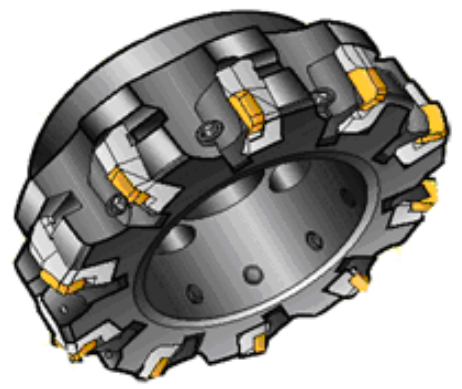

Figure 2. Face milling cutter

The circumference of the three face milling cutter has a main cutting edge, and the two sides face also have an assistant cutting edge, which improves the cutting condition, improves the cutting efficiency, and improves the surface quality.

Three face milling cutter is shown in Figure3

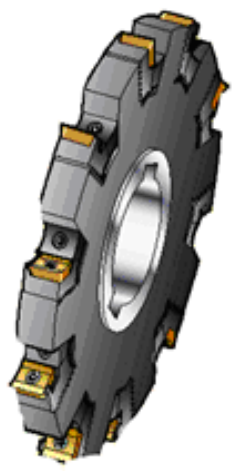

Figure 3. Three face milling cutter
The pitch types of the indexable blade are divided into three types, unequal sparse pitch, close pitch and super dense tooth.

When the stability and power is limited in order to achieve the highest productivity, unequal pitch can be used to reduce the number of blades for a long time processing. The unequal tooth spacing is suitable for processing long chip metal, such as aluminum alloy and stainless steel. Unequal pitch is beneficial to the vibration reduction of milling. The number of blades can be increased by using super dense teeth in the steady working condition, and the optimal production effect can be obtained, the processing is more suitable for short chip materials and heat resistant materials. Super dense tooth milling cutter production efficiency is high, but also the most suitable for processing cast iron and other fine scrap metal, but it requires high machine power and clamping stability. The performance of close pitch is between the above two.

\section{Selection of cutter blade}

The indexable blade is a functional element which is composed of a variety of rotatable cutting tools. Milling performance depends on the performance of the selected blade. Therefore, select the right indexable blade is very important for the overall cutting performance of the tool.

Rough machining is best to use compacting blade, which can reduce the processing cost. Dimensional accuracy and the sharpness of the compacting blade are not as good as grinding blade, But the compacting blade's edge strength is better, The rough milling need high impact resistance and larger cutting depth and feed speed, A roll chip groove is in the front cutter face of the blade, which can reduce the cutting force, the friction between the workpiece and the chip and the power. [4]But compacting blade surface is poor in dimensional accuracy and not as compact as grinding blade, and the milling cutter tips are highly inconsistent. Because of the low production cost of the compacting blade, it is widely used in production.

The best choice for fine milling is grinding blade, it has a good size precision. The positioning accuracy of the cutting edge in milling is high, which can obtain higher machining precision and lower surface roughness value. In addition, the development trend of grinding blade for finishing is grinding volumes chip groove, forming a large is rake angle cutting edge, allowing the blade in the small feed, small depth of cutting quantity. Without sharp anterior horn of the hard alloy blade, when the small feed, small depth of processing capacity, the tip will be frict to workpiece reducing tool life.

\section{Positioning and clamping structure of indexable blade}

Positioning of indexable blade which is to determine the position of the blade on the cutter body, so that the blade can keep the original size and precision of the blade when converting the new cutting edge or the new turning blade. Therefore, first of all, it should ensure the reliable 
positioning of the blade and the positioning accuracy. General should pay attention to the followings:

1) The positioning of the blade make sure that the cutting force should be in the range of the support surface of the blade, and it should be in accordance with the principle of positioning and clamping for cutting force.

2) Blade size positioning needs to meet the three point positioning principle.

The clamping way of the indexable blade is influenced by the shape of the blade, the size of the tool, and the situation of the use of the cutter.

Indexable inserts for clamping requirements of cutting force and clamping force of the force or the resultant force on the locating datum produced friction must to be greater than that caused by the centrifugal force generated in the cutting vibration and cutter the blade from the location of datum plane alternating force.

There are many forms of indexable inserts of the clamping mechanism, the mainly used is eccentric type, lever pin type, wedge type, pressure, pressure hole and vertical installation type etc.

\section{Geometric angle of milling cutter}

For milling cutters, it is very necessary to select the appropriate cutting angles for different materials and different shapes of the workpiece. The geometric angle of the milling cutter is shown in Fig4

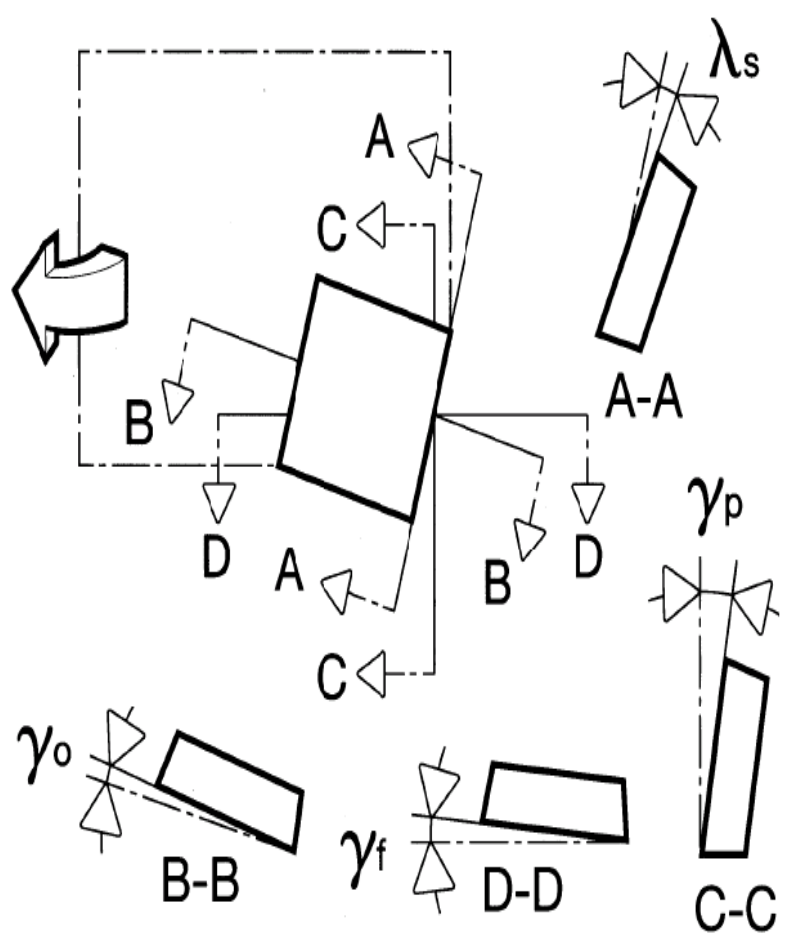

Figure 4. Geometric angle of milling cutter
Axial rake angle determines the direction of chip removal. Radial rake angle determines the cutting edge of the cutting edge.

When the Rake angle is positive, the discharge of the chip is better, but the tip of the cutting edge strength decreases. [5] Rake angle determines the degree of sharp cutting edges. Rake angle determine sharpness. Larger angle, better machinability, the chip is not fusible attached, When the negative angle is large, the cutting performance is poor, but the cutting edge of the cutting edge is high.

When axial rake angle and Radial rake angle are negative, it is suitable for milling cast iron and hard material. When axial rake angle and Radial rake angle are positive, it is suitable for milling the Aluminum Alloy. When axial rake angle is positive and radial rake angle is negative Suitable for milling of hardened steel.

The development of milling machine clip has gone through several stages

1) Plate blade. At this time, the cutter body is designed for axial negative rake angle.

2) Blade with back angle. The milling by shear processing instead of the original pushes processing.

3) Blade with back angle and the chip breaking groove is easy to chip breaking. The volume of the tool chip can be reduced, and the number of the blades is increased, and the chip flow direction can be easily controlled.

4) Blades with mounting holes. The cutter blade is clamped on the cutter body by screws; it is beneficial to increase the number of blades on the cutter body which requires high precision. The cutter body is usually processed after harden process.

5)The bellowing aspect should be considered in the selection of the blade: the blade shape, the main cutting edge angle, precision cutting blade, a blade fixed form, blade cutting edge length, thickness of the blade, blade cutting edge section shape, blade broken flutes etc.

\section{References}

1. D.P. Liang. WSTL, 68 (2008):243-245.

2. B. Bazrov, E. Z. Nasirov. RERV.27 (2012):95-97.

3. Dvorak, Paul. Machine Design (2005):115-116

4. Hj. Yang .EMT, 5(2011):8-10.

5. X. Zhang, Y. Zhang, DH .Liu .STI 14(2012):95-97.

Among them: $\gamma_{\mathrm{P}}$ is Axial rake angle,

$\gamma_{f}$ is Radial rake angle,

$\gamma_{\mathrm{o}}$ is Rake angle

$\lambda_{\mathrm{s}}$ is Cutting edge inclination 